\title{
Media Information Literacy to Produce Collaborative Social Capital
}

\author{
Masami Yoshida and Jun Iijima
}

\begin{abstract}
In the ubiquitous cyber communication society, vernacular creators participate a creative community on social media and use collaborative methods of production that are different from traditional industrial modes. This study investigates advanced media information literacy (MIL) competency for collaborative creation. A well-known case was examined, and the analysis provides a deeper understanding of interrelated factors in mixed media creation. We also extracted disruptive technologies that blur the borders between vernacular and professional production in quality. The results show that creators have more fun in making work themselves than in making profit. Users also show benevolence and make contributions to expand the community. There is importance in understanding entrepreneurship and the community in which creators cooperate with industries. We conclude that social capital resides in the connection of users. The competency of socialized creation as an advanced MIL competency is also discussed in the context of four pillars of items: socialized creation, collaborative creativity, critical eye, and building affordance.
\end{abstract}

Index Terms-Collaborative creativity, creator's competencies, digital entrepreneurship, media information literacy, produsage.

\section{INTRODUCTION}

A challenge for educators is to move beyond thinking of information technology (IT) or IT-enabled education platforms as a tool. Instead, we need to think about how to nurture citizens' ability and confidence to excel both online and offline in a world where digital media is ubiquitous. The field of creativity has experienced significant changes as IT penetrates all aspects of our life.

In 2013, UNESCO proposed media information literacy (MIL) for citizens as a required competency for living in an information society [1]. The highest component is creation, which involves the following competencies [2]:

1) Creating and producing new information, media content, or knowledge for a specific purpose in an innovative, ethical, and creative manner.

2) Communicating information, media content, and knowledge in an ethical, legal, and effective manner using appropriate channels and tools.

3) Engaging with media and information providers for self-expression, intercultural dialogue, and democratic

Manuscript received August 11, 2019; revised October 12, 2019.

M. Yoshida is with the Faculty of Education, Chiba University, 1-33 Yayoi, Chiba, 263-8522 Japan (e-mail: yoshida-m@faculty.chiba-u.jp).

J. Iijima is with the Graduate School of Social Sciences and Humanities, Chiba University, 1-33 Yayoi, Chiba, 263-8522 Japan (e-mail: afca8964@chiba-u.jp). participation through various means in an ethical, effective, and efficient manner.

4) Monitoring the impact of created and distributed information, media content, and knowledge, as well as using existing media and other information providers.

Similarly, the digital intelligence quotient (DQ) framework was invented by Park in 2016 [3]. DQ measures a set of skills needed to meet the demands and challenges of the digital world, including digital citizenship and literacy skills [4], and has been adapted by of the Organisation for Economic Co-operation and Development's (OECD's) Education 2030 and the United Nation's Sustainable Development Goals (UN SDGs) [5]. The following three levels of DQ were proposed.

Level 1: Digital citizenship

Level 2: Digital creativity

Level 3: Digital entrepreneurship

DQ is targeted toward 8 to 12 -year-old children, parents, and educators. Digital entrepreneurship has been discussed as the ability to use digital media and technologies to solve global challenges and create new opportunities [4]. It advocates more contemporary competence than MIL, where users are expected to evolve competencies under existing media service frameworks in an ethical, legal, and effective manner, as shown in MIL creation competencies 1-3, as well as understanding existing media and information providers, as shown in competence 4. Clearly, under the rise of social media environments, the intent of level 3 of DQ is to have a profound impact on the production of social capital, business, and legal frameworks, as well as the democratic society itself.

Novel MIL should consider that citizens not only participate in society but also begin start-ups within it. By addressing the transformational changes in media production and related competencies, this study draws on the post-creation competency that is emerged in MIL, which requires collaborative creativity in social media environments.

Grounded theory was used in data collection to perform rigorous, inductive investigation and theory building [6] through computer program ATLAS.ti 8.

\section{Social Media as Platforms of Social Capital}

Collaborative social media provides a novel indicator of the growing importance that users place on user-generated content (UGC) and its distribution. Creative content sites such as Flickr and YouTube, the decentralised discussions of the wider blogosphere, and the software development 
communities of the open source movement all serve as examples of this now well-established trend towards the development of a new path of production, business, governance, and community models, which are significantly aided by the simultaneous deployment of increasingly sophisticated social media [7].

Perhaps this is ultimately no more than a stunt - an attempt by a media production corporation to cooperate with a section of "the people formerly known as the audience" [8], who had been alienated from the production path of mainstream commercial media. In this path that has emerged, many creators utilise online platforms to collaborate in the development and continuous improvement of mixed media contents, and this work takes place through a series of more or less unplanned, ad hoc, almost random cooperative encounters. These processes can thus be described using the term "produsage" [9].

\section{A. Produsage}

The portmanteau "produsage" was constructed by Bruns from "production" and "usage" to emphasize the inherent role of potential participants in these processes as active users of content and information rather than merely as passive consumers [10]. The concept of produsage includes "the collaborative and continuous building and extending of existing content in pursuit of further improvement" [11]. It also differs from widespread hackathons (a portmanteau of the words "hack" and "marathon"), which are group work by diverse creators, and it includes exploratory joint work under the production process of commercial media. The process of produsage in myriads of enthusiast communities no longer involves producing content, ideas, and knowledge in a way that resembles traditional, industrial modes of production. Produsage exhibits the following aspects [12]:

1) Community-based: Produsage proceeds from the assumption that the community as a whole, if sufficiently large and varied, can contribute more than a closed team of producers, however qualified they may be.

2) Fluid Roles: Producers participate as appropriate for their personal skills, interests, and knowledge, which changes as a produsage project proceeds.

3) Unfinished artefacts: Content artefacts in produsage projects are continually under development and, therefore, are always unfinished; their development follows evolutionary, iterative, palimpsest paths.

4) Common property, individual merit: Contributors permit (non-commercial) community use, adaptation, and further development of their intellectual property and are rewarded by the status capital they gain through this process.

In this context, it is necessary to develop flexible academic environments that cultivate collaborative, creative, critical, and communicative competencies [13].

\section{B. Collaborative Creativity}

Condry analysed creativity in social media and found that the connections and actions of a community are more central than the "message" or the "means of transmission" [14]. Collaborative creativity is explored by groups rather than individuals [15]. The groups are recognized to be located on social media, in a portable creative platform, and across various media and communities of fans and creators alike [16]. It focuses especially on a more interaction-oriented account of the collective work rather than merely outcomes and products, and a multiplicity of processes and interactions are analysed to interpret collaborative creativity. Music also provides the opportunity to work collaboratively to generate a shared creative product, engaging participants in cooperative tasks [17]. Shneiderman proposed the following creative online activity stages [18]:

1) Collect: Gather Information and acquire resources

2) Relate: Work in collaborative teams

3) Create: Develop ambitious projects

4) Donate: Produce results that are meaningful to others

These stages are an essential part of collaborative creativity and referred to as collaborative creativity techniques [19].

\section{A FAMOUS CASE}

In 2007, the computer software Vocaloid Hatsune Miku (Miku) was released, in which the sampled voice of a famous voice actress, Saki Fujita, was encoded by Crypton Future Media (Crypton) in Japan [20]. "Vocaloid" is a portmanteau that blends "vocal" and "android" and refers to music synthesis software in which users enter lyrics and melodies to make music with computer singing. Since anyone with Vocaloid software can produce music without a real singer, it allows amateur users to be introduced to the music production arena outside of the existing commercial-media production path. Increased amateur creators are gathering together around Miku in a growing community on a social media called Nico Nico Douga (Nico).

\section{A. Communication on Social Media}

Nico is a unique video sharing social media that has become a space for crowd-sourced innovation driven by "neoliberal greed" [14]. There are similar social media platforms for video sharing services such as YouTube are widely used for UGC and commercial music promotion. However, Nico has the following distinctive features that have never appeared in other social media. Nico allows users to embed comments directly into a video feed, and all posted comments are made diachronically appear synchronically. When the next user watches a video, posted comments simultaneously appear with a timeline. Thus, Nico conveys the impression of a shared viewing experience [21]. It provides a platform for virtual public viewing and discussion, and the video timelines virtually synchronizes all users who access a video asynchronously.

At the genesis of Nico, many users posted commercial videos and music without permission to enjoy communication. Nico deleted illegally uploaded contents immediately, and users sought other contents to continue their communication. Conveniently, after Miku was released, many amateur creators uploaded their original music, and users thought that this was what they have waiting for. Users 
also reconfirmed the importance of Nico, where they can have communication through sharing viewing experiences [22]. Their activities showed concrete characteristics of aspect 1 of produsage, of which the Miku community is recognized as a remarkable example [23].

\section{B. From Copyright to Licence}

Crypton noticed the growing Miku community and decided not to control the use of images of Miku on packages to enhance their derivative works [14]. This farsighted decision enhanced the following of a huge number of collaborative mixed media creations featuring the Miku image. Thereafter, derivative works of Miku appeared.

To accelerate collaborative creation, Crypton opened the Piapro website (a name derived from "peer production") to establish agreements about the use of products (music, illustration, text, and 3D model) that are similar to the Creative Commons license [24], and creators could choose a set of conditions that they wish to apply to their products. This license is called the Piapro Character Licence (PCL).

\section{Benevolence}

Miku songs that were posted early on appeared with mixed media, such as title cue cards, short animated sequences, or static images (illustrations) of Miku [23], as well as a few posts by exceptionally savvy users of videos of 3D graphics. This is a concrete case of aspect 2 of produsage and stages 2 and 3 of collaborative creativity. Subsequently, productions of 3D graphics were emphasized by Miku Miku Dance (MMD), which is freeware created by the independent developer Higuchi. MMD allows fans to make choreography and animate videos, even without knowledge of 3D animation [21]. This is a concrete case of aspect 4 of produsage and stage 4 of collaborative creativity.

The results of previous studies on communication in social media depicted benevolence as a core of user behaviour [25]. Benevolence leads people to unselfish and kind-hearted behaviour that engenders and promotes recognition and reciprocity and, in doing so, earns the goodwill of those around them. This is the hub of social networking with a purpose, mission, and a genuine intent to grow communities based on trust, vision, and collaboration. At a glance, benevolence appears similar to aspect 4 of produsage, but no reward is intended in benevolence. The goodwill of users is explained from a user-centred view and offers a more acceptable explanation of the growing community of this case.

\section{Participatory Theatre}

"Participatory theatre" is where audiences become involved in a production in the context of civic collaboration of pluralistic media, the interaction of information, media, and culture. As an example, Horton focused on a case in Jemaa el-Fnaa square in Morocco, which is on the list of the world's Intangible Heritage Sites [26]. The square is a multifaceted cultural space where people can see cultural performances through musical, religious, and artistic expressions. The square is also a meeting point for both the local population and people from elsewhere. In addition, a variety of services are offered, such as dental care, traditional medicine, fortune-telling, preaching, henna tattooing, water-carrying, and the sale of fruit and traditional food. On the other hand, while the square enjoys great popularity, the cultural practices suffer acculturation. This case of participatory theatre shows a great example of the collaboration of unstructured distributed activities by socializers and visitors.

While the community of Miku is formed by posted music as a trigger, derivative products have emerged from distributed creators who were introduced to mixed media in Nico with tacit understanding [27]. Nico is a case with a virtually developed platform of participation theatre through the collaboration of unstructured distributed activities by creators and audiences. The products disseminated are not only music, video, and illustration, but also human singers or instrumentalists performing Miku songs, costume play, storytelling, and dance covers. This participatory theatre implies the importance of the unspoken agreement among users to join the collaborative arena. The participatory theatre is also a case of aspect 2 of produsage and stages 2 and 3 of collaborative creativity. While a target inheres in produsage, participatory theatre demands more depth of focus from the community of users and creators.

\section{E. Doujin}

To understand the evolution of the Miku community, there is unmissable domain called Doujin, which appeared in a fan society [20]. Doujin is a term for a group of people or friends who share an interest, activity, hobbies, or achievements. Originally, the word doujin was used to refer to amateur self-published works, such as manga, novels, fan guides, art collections, music, anime, and video games. An ethnographic study reported that the motivation of doujin was primarily "because making works itself is fun (49.8\%)," and only limited members seek income "to make money by selling their works $(0.8 \%)$ " [14]. Offline doujin events were disseminated, where creators published, sold, and communicated, and doujin members of social media had the opportunity to communicate. This congested mode of doujin is the reason why the Miku community could evolve with the involvement of a variety of creators and their activities [27].

At this stage, Nico users contributed to expanding user communication. The developed community is indeed the substantiated concept of O'Reilly's Web 2.0 in terms of "mass user participation, without approval of content by gatekeepers or editorial staff" rather than "publishing of online documents, once approved by gatekeepers and editorial staff." In fact, they enjoyed more clicks (communication strokes) than page views (content) [28]. The phenomena can also be explained by the recent educational theory of connectivism. Learning can reside outside of ourselves, it is focused on connecting specialized information sets, and the connections that enable us to learn more are more important than our current state of knowing [29]. Knowledge resides in a distributed manner across a network [30].

\section{F. Transformation of Business Model}


Christensen coined a term the "disruptive technology" as an idea for the business world as a new technology that displaces an established technology and shakes up the industry, or a ground-breaking product that creates a completely new industry [31]. Before the Miku community emerged, the established music industry had a robust system for producing music. However, UGC music is expanded as a communication enhancer in Nico. Online platforms and Nico became teeming with the products of everyday digital creativity. Additionally, professional artists also posted their products on Nico, further blurring the boundaries between professional and vernacular creativity and engaging in complex collaboration in mixed media.

In the collaborative social media environment, the production of music is being creatively configured. New technologies, including new modes of production by Miku, are leading to changes in contemporary production. Regarding Miku doujin, more than 100,000 songs are released on Nico, and more than 600,000 creators are registered on Piapro [24]. After Crypton noticed the power of the Miku community, they officially adopted these fan-made derivatives and struck commercial deals with their creators to produce merchandise and include them in the project [32]. Crypton started new music label called Karent (derived from "Karen Toffler") to cultivate creators for the commercial music scene in 2008. Now, they have recruited more than 250 creators and 3,500 songs from the 100,000 songs on Nico [24]. Furthermore, various commercial works appeared, including figurines, games, character-related merchandise, fan events, and live band performances with a wider holographic screen image of the Miku character dancing, and CD/DVD/Blue-ray discs [21, 33]. The Miku market has thus grown by more than $\$ 100$ million US per year [34].

\section{DISCUSSION}

Our case study crosses a variety of diverse domains of information, knowledge, creative works, and commercial use. The observations demonstrated the substantial potential for the needs of advanced MIL competency of user-generated, collaborative content creation. In the following sections, we discuss the new MIL competency, four pillars of items, and the related theoretical foundation.

\section{A. Competency of Socialized Creation}

According to our findings in a case, the following items of are proposed for the competency of socialized creation:

1) Socialized creation: Media-information-literate socialized creators are able to create/produce and release information or media content with attractive qualities in society in an innovative and creative manner.

2) Collaborative creativity: Media-information-literate socialized creators can collaborate with information, media content, and knowledge with diverse creators under heterarchical and fluid connections, contribute to the growth of the community, and have social, professional, and ethical responsibility.

3) Critical eye: Media-information-literate socialized creators engage in communication and have a critical stance towards potential collaborators and the creator's own work to contribute effective collaborative creation through various means in an effective and efficient manner, as well as make impartial agreements with other creators.

4) Building affordance: Media-information-literate social creators understand and propose trends in terms of information, media content, knowledge production, and use, and they understand how media and information products of UGC introduce benefit to industries.

The platform of content creation involves large communities of users who act without a controlling and coordinating hierarchy. While flexible, heterarchical and organized ad hoc communication is deployed in the on-going process of production, and users are more closely aligned with the emergent community principles than with the predetermined, supposedly optimized rigid structures of governance in industries. The stability of principles in ethical and legal manners does not arise from rigid regulations but from opinions of diverse individuals. This is why we regard ethical issues as constructive, but not complying.

\section{B. Social Capital Resides in Communication}

The case investigation reveals more importance in the evolution of communication platforms than content. Similarly, there are emerging business strategies in information society based on systems of engagement (SoE), in which information systems enable expansion of the market using connections with external users through the continuous development of enterprises. Co-creation is an effective method for SoE that involves users in product development and innovation, and it is gathering attention. In the policy of SoE, content is recognized as communal governed by collaboration and online conversation [35]. Capital is no longer authored, but it resides in social community. We must keep in mind that social life and activity are the "factory" for post-industrial economies [33].

Indeed, there are bilateral domains of $\mathrm{SoE}$ and doujin in the case study. Fig. 1 shows the framework with a triad of elements of social capital, where the structure of collaborative creation is involved. The framework explains the coexistence of derivative commercial and non-commercial products. To do this, it was essential to contribute to expanding the community and maintaining the communication platform by all players. Various evidence was observed in the case study. Particularly, doujin was contributed not only on Nico, but also in offline events, and communication among users resulted in expansion. Industries also offered fan events and a concert with a virtual singer screen, as well as allowing freedom of derivative works.

This explains the importance of growth, as shown in item 2 of socialized creation. In addition, as mentioned in item 3 regarding $\mathrm{DQ}$, it is necessary to have competencies to produce social service using technology. While creators develop a product collaboratively, they need to understand the raison d'être (reason of being) of their product in the 
society. The gist of this importance is embedded in item 4 of socialized creation.

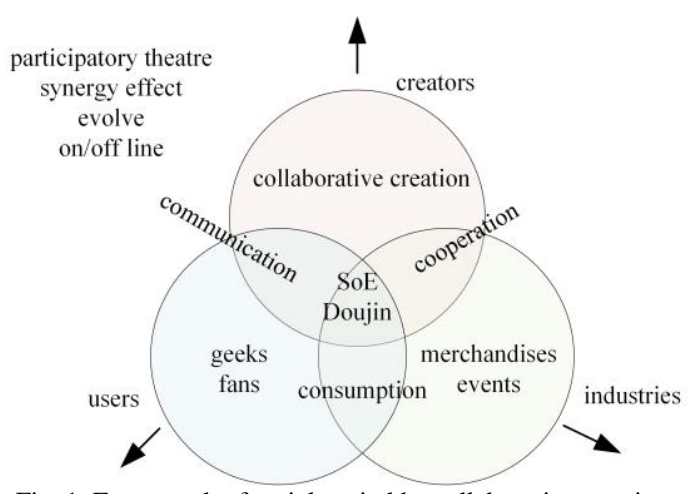

Fig. 1. Framework of social capital by collaborative creation.

The actions of industries were not only based on the understanding of human nature and the lenient decision, but also enacting the policy of SoE that should contribute to the evolution. Information that serves as a useful reference for socialization competency is seen in technopreneurship, which is a relatively new term that is frequently used in hackathons in industries and business, as well as at the beginning of SoE. A technopreneur distinguishes logic from tradition, tradition from prejudice, prejudice from common sense, and common sense from nonsense while integrating a variety of ideas from diverse groups and disciplines [36]. Arora listed 13 abilities of technopreneurship that need to be acquired by university students [37]. The following abilities can be extracted:

- Bringing the right people together and establishing a supportive infrastructure such as a space to meet and collaborative technologies.

- The ability to communicate effectively to a radically, culturally, and professionally diverse group of people.

Surprisingly, these abilities of the business field suit with our proposed socialized creation competence (item 2) and showed a high affinity. Socialized creators also need to recognize the culture of industries, which is also transformative learning content.

\section{Collaborative Intelligence and Collaborative Creativity}

In the case study, users enjoyed communication. Nevertheless, the quality of the product that attracted a greater audiences more quickly than other products in the niche community was indispensable. Indeed, their creations were a focus that attracted artistic quality, which could be accepted successfully by derivative creators and audiences. This important point is included in item 1 of socialized creation.

In the collaborative development process, collaborative intelligence has been widely configured in education. So far, many preceding studies in schools have praised collaborative group work and collaborative intelligence. Although a number of examples of group work have led to exceptional achievements, individuals and groups often underperform on innovation tasks, and much evidence suggests that group interaction may often hinder innovation [38].
On the other hand, collaborative creativity in social media allows more open engagement and focuses on the convergence of self-initiated activities of creators and collaboration with creators of derivative works. Mixed media was processed under the elaboration of products. As effects of the collaboration style of creators, a preceding study concluded that geographically dispersed locations are better than one location to collaborate and increase the quality of a product, and differing locations permit an independence from which divergent perspectives and creativity are likely to be enhanced [39]. This explains the reason for the collaborative Miku production processes effectively by the style of mixed media production on Nico, and it also supports the needs of item 1 of socialized creation.

Reilly proposed prerequisites of collaborative creativity [40], and some of the following items are entailed in items 2, 3 , and 4 of socialized creation:

- Idea-sharing is a high priority for tacit knowledge transfer.

- Knowledge workers need to be pulled instead of pushed and suppressed.

- Knowledge from knowledge workers should be openly exchanged and recognized.

\section{CONCLUSION}

The proposed competency exists within a wider context of new and emerging concepts for adapting the technological, social, and business environment of UGC creation. A learning approach structured with this MIL competency no longer follows a paradigm of commercial production and user transmission. Instead, it turns learning into a more communal, networked process.

\section{CONFLICT OF INTEREST}

There are no conflicts of interest to declare.

\section{AUTHOR CONTRIBUTIONS}

Yoshida presented the idea, devised the project, contributed to the implementation of the research, and wrote the manuscript. Iijima assisted in collecting data and the analysis of section III.

\section{REFERENCES}

[1] A. Grizzle, P. Moore, M. Dezuanni, S. Asthana, C. Wilson, F. Banda, et al., Media and Information Literacy: Policy and Strategy Guidelines, Paris: UNESCO, 2013.

[2] UNESCO Communication and Information Sector, Global Media and Information Literacy Assessment Framework. Country Readiness and Competencies, Paris: UNESCO, 2013, pp. 57-59

[3] Y. Park. (May 2019). 8 digital life skills all children need - and a plan for teaching them. [Online]. Available: https://www.weforum.org/agenda/2016/09/8-digital-life-skills-all-childr en-need-and-a-plan-for-teaching-them $/ 2016$

[4] DQ Institute, Digital Intelligence $(D Q)$. A Conceptual Framework \& Methodology for Teaching and Measuring Digital Citizenship, Singapore: DQ Institute, 2017.

[5] DQ Institute. (June 2019). What Is the DQ Framework? Global Standards for Digital Literacy, Skills, and Readiness. [Online]. Available: https://www.dqinstitute.org/dq-framework/ 
[6] B. G. Glaser, A. L. Strauss, and E. Strutzel, "The discovery of grounded theory; strategies for qualitative research," Nursing Research, vol. 17, no. 4, p. $364,1968$.

[7] A. Bruns, "Produsage, generation C, and their effects on the democratic process," 2007.

[8] J. Rosen. (May 2019). The people formerly known as the audience. [Online]. http://archive.pressthink.org/2006/06/27/ppl_frmr_p.html

[9] A. Bruns and J.-H. Schmidt, "Produsage: A closer look at continuing developments," New Review of Hypermedia and Multimedia, vol. 17, no. 1, pp. 3-7, 2011.

[10] A. Bruns, Blogs, Wikipedia, Second Life, and Beyond: From Production to Produsage, New York: Peter Lang, 2008

[11] A. Bruns, "Beyond difference: Reconfiguring education for the user-led age," presented at the ICE 3 (Ideas, Cyberspace, Education) Conference, Ross Priority, Loch Lomond, Scotland, 2007.

[12] A. Bruns, "The future is user-led: The path towards widespread produsage," Fibreculture Journal, no. 11, 2008

[13] C. Holotescu, "A conceptual model for open learning environments," in Proc. International Conference on Virtual Learning-ICVL, pp. 54-61, 2015.

[14] I. Condry, "Post-3/11 Japan and the radical recontextualization of value: Music, social media, and end - around strategies for cultural action," International Journal of Japanese Sociology, vol. 20, no. 1, pp. 4-17, 2011.

[15] M. C. Nadal, "Real virtuality: An examination of digital identity and the ethical boundaries and benefits of appropriation in "real": Concerto for vocaloid," CA: California State University, Long Beach, 0438258088 , 2018.

[16] I. Condry, The Soul of Anime: Collaborative Creativity and Japan's Media Success Story, Durham: Duke University Press, 2013.

[17] M. Biasutti, "Creativity in virtual spaces: Communication modes employed during collaborative online music composition," Thinking Skills and Creativity, vol. 17, pp. 117-129, 2015.

[18] B. Shneiderman, Leonardo's Laptop: Human Needs and the New Computing Technologies, MA: Mit Press, 2003, pp. 83-87.

[19] J. Salmons, Handbook of Research on Electronic Collaboration and Organizational Synergy, IGI Global, 2008, p. 87.

[20] C. King, The Unauthorized Guide to Japanese Entertainment, Including Anime, Manga, and J-Pop, USA: Webster's Digital Services, 2011.

[21] A. M. Sousa, "Beauty is in the eye of the "produser": Japan's virtual idol Hatsune Miku from software, to network, to stage," Media Convergence in Japan, Connecticut, US: Kinema Club, 2016, pp. 117-128.

[22] T. Shiba, Why Did Hatsune Miku Change the World? Tokyo: Oota Publishing, 2014.

[23] A. Leavitt, T. Knight, and A. Yoshiba, "Producing Hatsune Miku: Concerts, commercialisation, and the politics of peer production," Media Convergence in Japan, Connecticut, US: Kinema Club, 2016, pp. 200-229.

[24] S. Uchida, "Hatsune Miku ga umu creation no rensa wo sasaeru sikumi" [Mechanizm to support productional chain brought from Hatsune Miku]," Monthly Art Magazine Bijutsu Techo, vol. 65, no. 985, pp. 78-87, 2013

[25] B. Solis. (2013). Behaviorgraphics humanize the social web. [Online]. Available:

http://www.briansolis.com/2010/03/behaviorgraphics-humanize-the-soci al-web/

[26] F. W. J. Horton, "Muses on information literacy, Media literacy and intercultural dialogue: A coffee and tea shop application," Media and Information Literacy for the Sustainable Development Goals, Sweden: International Clearinghouse on Children, Youth and Media, Nordicom University of Gothenburg, 2015, pp. 219-227.

[27] S. Suzuki, "Syumi to online community. 'Hatune Miku' ni miru volunteerism no genzai" [Hobby and online community. Present volunteerism shown in 'Hatsune Miku']," Sociology of Being Connected and Not Being Connected, Tokyo: Koubundou, 2014, p. 275.

[28] T. O'Reilly. (June 2006). What is web 2.0? [Online]. Available: http://www.oreillynet.com/pub/a/oreilly/tim/news/2005/09/30/what-is-w eb-20.html

[29] G. Siemens, "Connectivism: A learning theory for the digital age. elearnspace," International Journal of Instructional Technology and Distance Learning, vol. 2, no. 1, pp. 1-8, 2004.
[30] R. Kop and A. Hill, "Connectivism: Learning theory of the future or vestige of the past?" The International Review of Research in Open and Distributed Learning, vol. 9, no. 3, 2008.

[31] C. M. Christensen, The Innovator's Dilemma. When New Technologies Cause Great Firms To fail, MA: Harvard Business Review Press, 2013

[32] A. M. Sousa, "Beauty is in the eye of the 'produser': Japan's virtual idol Hatsune Miku from software, to network, to stageusa," Post-screen: Intermittence + Interference, pp. 117-128, 2016.

[33] P. W. Galbraith and J. G. Karlin, "Introduction: At the crossroads of media convergence in Japan," Media Convergence in Japan, Connecticut, US: A Kinema Club, 2016, pp. 1-29.

[34] Yano Research Institute. (2019). Increasing trend of animation market and idol market in major fields of 'wotaku'. [Online]. Available: https://www.yano.co.jp/press-release/show/press_id/2070

[35] G. Moore, "Systems of engagement and the future of enterprise IT. A sea change in enterprise IT," MD: AIIM, 2011.

[36] M. Cereijo. (2019). Technopreneurship. [Online]. Available: http://entrepreneurship-for-all.blogspot.com/2008/06/technopreneurship. html

[37] V. K. Arora and N. Arora, "Converging paradigms in behavioral and social engineering," Recent Trends in Social and Behaviour Sciences, Boca Raton, FL: CRC Press, 2014, pp. 3-8.

[38] P. B. Paulus, "The group creative process as a basis for team and organizational innovation," Social Dimension of Creativity. Towards the Development of Comprehensive Policy on Creative Talents, Sejong, Korea: Krivet, 2014, pp. 15-36.

[39] C. J. Nemeth and J. A. Goncalo, "Creative collaborations from afar: The benefits of independent authors," Creativity Research Journal, vol. 17, no. 1 , pp. 1-8, 2005.

[40] P. Reilly, "Get the best out of knowledge workers," People's Management Magazine, 2005.

Copyright (C) 2019 by the authors. This is an open access article distributed under the Creative Commons Attribution License which permits unrestricted use, distribution, and reproduction in any medium, provided the original work is properly cited (CC BY 4.0).

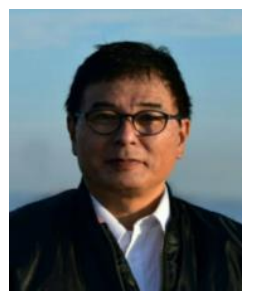

Masami Yoshida's major field is educational technology and education for international understanding. He used to work for the Faculty of Education, Toyama University, and did studies regarding educational technology. Then, he moved to the National Institute of Multimedia Education (NIME) and was involved in a project to study faculty development and distance education. He also contributed to Japan International Cooperation Agencies (JICA) as a training expert in Thailand, Malaysia, and Papua New Guinea. Recently, he gave instruction to directors of educational TV in African, South American, and Asian countries at the JICA Okinawa training centre. As his social contribution activities, he is an executive member of the All Japan Organization of Social Contribution (AJOSC) and the Association of Educational Information for International Communication (AEIIC). Now, he teaches in the Faculty of Education (B.Ed. course), Graduate School of Education (M.Ed. course), and Graduate School of Humanities and Studies on Public Affairs (Ph.D. course), Chiba University. He is also a guest Professor at Central China Normal University. His recent publication is "Information communication technology and changes of education," in Novel Situation of Education. Cp. 15, The Centre for Research and Development in Teacher Education, Faculty of Education, Chiba University (ed.), Tokyo: Hukumura Pub., 2018. Prof. Yoshida is also a member of the Japan Society for Educational Technology and the Japan Association for College and University Education.

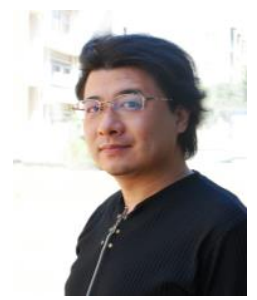

Jun Iijima is a Ph.D. candidate in the Graduate School of Social Sciences and Humanities, Chiba University, Japan. He is an authorized advisor for internet use licensed by the Internet Association. Iijima is a member of the Japan society for educational technology. He is a worker at A's Child Co., Ltd., and is active in music composition for short videos and documentaries. His recent study report is "A Study on Practice of Appreciation Class Applying YouTube: In Accordance with The Descent of Musicians Attempt to Visualize 'A Quotation of Music', Practical Research on the Education in Artificial Intelligence Society, pp.21-30, Graduate School of Humanities and Study of Public Affairs, Chiba University (in Japanese)." 